\title{
Diabetic Retinopathy - Need and Demand for Photocoagulation and its Cost-Effectiveness: Evaluation Based on Services in the United Kingdom
}

\author{
E. A. Savolainen and Q.P. Lee \\ Department of Community Health, London School of Hygiene and Tropical Medicine, London, UK
}

Summary. Photocoagulation services in the two Regions, north of the River Thames, treated 6,589 cases of diabetic retinopathy (including an annual incidence of 309 cases) or $20 \%$ of the estimated total need for photocoagulation. Sixty-one percent of diabetic retinopathy patients have disease in both eyes. It is cheaper to treat a patient with diabetic retinopathy than to look after a blind person for one year. Hence, adequate training in the identification and early treatment of diabetic retinopathy requiring photocoagulation is urgent.

Key words: Diabetic retinopathy, photocoagulation services, cost-effectiveness.

Table 1. Estimates of the patient pool in need of photocoagulation treatment in the two Regions

7.1

million

(b) Prevalence of known diabetes

(c) Incidence of diabetes per year

(d) Prevalence of any diabetic retinopathy in diabetes

(e) Proportion of treatable diabetic retinopathy of all diabetic patients

(f) Prevalence of treatable diabetic retinopathy in diabetic patients

(g) Incidence of any diabetic retinopathy in population

(h) Incidence of treatable diabetic retinopathy per year in general population

(i) Proportion of all treatable diabetic retinopathy having $61 \%$ bilateral disease that requires treatment

(j) No. of eyes requiring photocoagulation (total patient Patients pool)

6.4 per 1,000

30 per 100,000

(1) $23 \%$

(3) $29 \%$

(4) $47 \%$

$50 \%{ }^{\mathrm{b}}$

8.7 per 100,000

4.35 per

100,000

$61 \%$
(2) $36.8 \%$

(1) $11.5 \%$

(2) $18.4 \%$

(3) $14.5 \%$

(4) $23.5 \%$

per year

per year

a Percentage of all diabetic patients multiplied by percentage having retinopathy derived from data obtained from Oakley et al. [7]

b Proliferative retinopathy and treatable proportion of background retinopathy
Source

No. patients within the two Regions studied

$\begin{array}{lr}\text { Regional Health Authority } 1978 & \\ \text { Birmingham diabetic survey } 1962[3] & 45,440 \\ & \\ \text { Birmingham diabetic survey 1970 [8] } & 2,130 \\ & \\ \text { Donovan } 1978 \text { [9] } & 10,450 \\ \text { Radcliffe Infirmary diabetic clinic 1962 [10] } & 16,722 \\ \text { Probability estimate } & 13,178 \\ \text { Probability estimate }^{\mathrm{a}} & 21,357\end{array}$

Radcliffe Infirmary diabetic clinic 1962 [10], Consultants' estimate

Applying 50\% to data from (d) $\quad 5,225$

8,361

6,589

10,678

(d) $(3) \times(c)$

Applying 50\% to data from (g)

309

Examination of case records in this study

4,019

(f) + (i) 
Estimated total number of patients with any diabetic retinopathy $(13,178)$ (from Table 1)

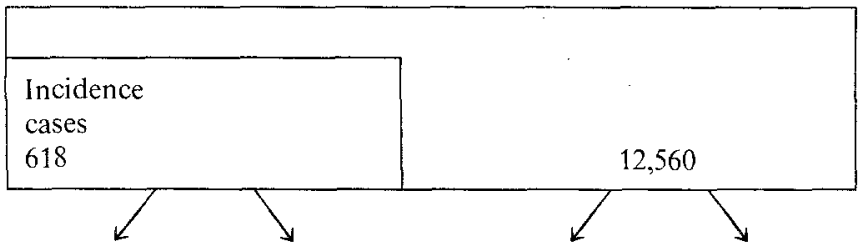

Distribution of patients with proliferative and background retinopathy (from proliferative minus background $=0.32$ ) (Donovan [9])

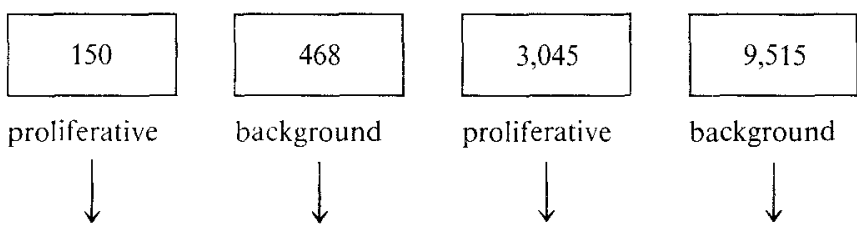

Number of cases with treatable diabetic retinopathy $(6,589$ patients) (from Table 1)

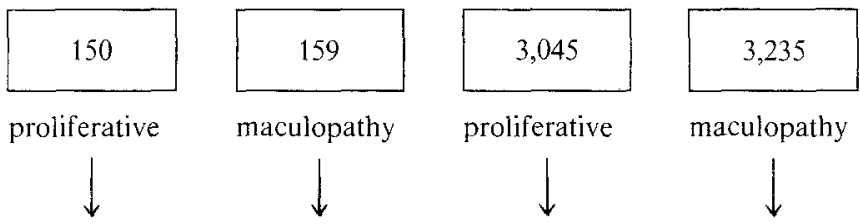

Number of eyes requiring photocoagulation treatment $(10,608$ eyes) (from sampled case records)

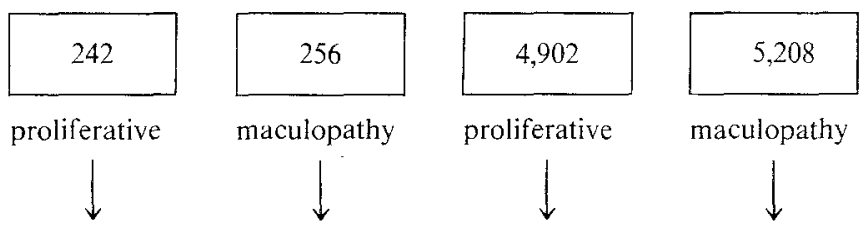

Total consultant time $(21,417 \mathrm{~h}$ ) (from consultants' practice of photocoagulation)

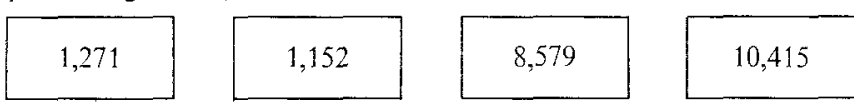

Fig. 1. A model for determining the present patient load for photocoagulation services per year

Two Regional Health Authorities (North-West, and the North-East Thames) measuring 1,284 square miles (2,054 square kilometres) and 1,600 square miles $(2,560$ square kilometres) requested the study. For every person diagnosed as diabetic, there may be another undiagnosed [1-3]. Three risk factors for diabetic retinopathy have been definitely identified: (1) the duration of the disease [2], (2) Type I (insulin-dependent) diabetes [2], and (3) the degree of hyperglycaemia [4-6]. Other risk factors suspected but not clearly demonstrated include genetic factors, racial and geographical variation, smoking, sex, hypertension, and socio-economic circumstances.

\section{Methods}

The estimated total number of diabetic patients in need of photocoagulation was calculated by applying published data to the home population of both Regions [2, 3, 7, 8]. In 1979, 272 case notes of diabetic retinopathy patients treated by photocoagulation in 1978 were sampled from nine out of ten photocoagulation centres (Hammersmith Hospital, Western Ophthalmic, Edgware General, Luton \& Dunstable, Charing Cross, South Middlesex, Moorfields Eye Hospital, St. Bartholomew's, North Middlesex, and St. Mary's, Cholchester). Fifty-two percent (141 case notes) were available for analysis. Interviews with consultants from all photocoagulation centres provided data on the number of photocoagulation sessions per week, and the number of eyes treated per session. Information regarding manpower, equipment, and consultants' practice of photocoagulation for different patient groups was obtained to develop a model for estimating total consultant hours and total treatments required per year.

\section{Results}

The total number of eyes in need of photocoagulation was estimated at 10,608 (Table 1). This required 21,417 consultant hours per year (Fig. 1), and 14,496 treatments. Using 84 photocoagulation hours weekly with an average of 2.5 photocoagulation treatments per $3 \mathrm{~h}$, 3,080 treatments were given in 1979. The cost of out-patient photocoagulation treatment and follow-up comes to $£ 60$ per eye per year, or $£ 100$ per patient per year (at $1981 / 82$ prices $-£ 170$ ). The cost of maintaining one blind person per year due to diabetic retinopathy (considering loss of average earnings and social security payments) comes to $£ 1,751$ per annum (at end of 1981 $=£ 2,871)$.

\section{Discussion}

The results have their limitations due to the unavailability of 131 case notes. The presence of Moorfields Eye Hospital and Hammersmith Hospital, which accept patients from outside their Regions, indicate that services have in fact met $<20 \%$ of the estimated total need for photocoagulation in the two Regions. The study suggests that either many patients with diabetic retinopathy remain undetected, or patients present themselves too late for effective treatment to be of use. There is an urgent need to set up stringent criteria for the need for photocoagulation, so that early detection, adequate treatment, and follow-up can be given. To meet this objective, it would be necessary to offer special training in photocoagulation to interested physicians, general practitioners, and possibly paramedical staff. As treatment is time-consuming, this would have enormous implications on use of manpower resources, particularly ophthalmological services. Out-patient waiting lists may lengthen. It would be helpful to have routine statistics of numbers of new and old photocoagulation cases to assess whether the provision of services needs to be altered.

Acknowledgements. We thank Drs. T.Cullinan, H.Sanderson and J.Roberts, and Professor R.F.L. Logan for helpful advice, and the consultants of the photocoagulation centres for interviews and permission to look at case notes. 


\section{References}

1. Burton BT, Hirshman GH (1980) Diabetes in the USA: a demographic overview. In: Freidman EA, L'Esperance FA (eds) Conference on diabetic-retinal syndrome. Grune \& Straton, New York, pp 5-17

2. Oakley WC, Pyke DA, Taylor KW (1975) Diabetes and its management. Blackwell Scientific Publications, Oxford, p 51

3. Report of the Working Party appointed by the Royal College of General Practitioners (1962) A diabetes survey. Br Med J 1: 1497-1503

4. Pirart J (1978) Diabetes and its degenerative complications: a prospective study of 4,400 patients observed between 1947 and 1973. Diabetes Care 1: 183-186

5. Tchobroutsky G (1978) Relation of diabetic control to development of microvascular complications. Diabetologia 15: 143-152

6. Dorf A, Ballintine EJ, Bennett PH, Miller M (1978) Retinopathy in Pima Indians. Diabetes 25: 554-560
7. Oakley WC, Pyke DA, Taylor KW (1975) Diabetes and its management. Blackwell Scientific Publications, Oxford, pp 124-125, 183

8. Report by the Birmingham Diabetes Survey Working Party (1970) Five-year follow-up report on the Birmingham diabetes survey of 1962. Br Med J 2: 301-305

9. Donovan RJ (1978) Prevalence of retinopathy in a diabetic clinic. Br Med J 1: 1441-1442

10. Caird PI, Pirie A, Ramsell TG (1969) Diabetes and the eye. Blackwell Scientific Publications, Oxford, pp 185

Received: 30 October 1981

and in revised form: 1 April 1982

Dr. Q. P. Lee

North West Thames Regional Health Authority

40 Eastbourne Terrace

London W2 3QR, UK 